\title{
TĂNG CƯờNG CÁC BÀI TOÁN CÓ NỘI DUNG THỤ̉C TIẼ̃N \\ TRONG DẠY HỌC TOÁN CHO SINH VIÊN Hệ CAO ĐĂNG SƯ PHẠM TOÁN
}

\section{Supplementing practical mathematic exercises in teaching math subject for students who are studying mathematic degree in teacher training college}

\author{
ThS. Dương Thị Hồng Hải * \\ ThS. Nguyễn Thị Hương Lan*
}

\section{TÓM TẮT}

Toán học, cũng nhu nhiều môn khoa học khác, phát sinh tì̀ thực tiễn, lấy thưc tiễn làm động lục phát triển và quay lại phục vu muc tiêu giải quyết các vấn đề thực tiễn. Đây là một trong nhũng co sở cho việc dạy và học Toán kết nối với thực tiễn. Việc chuẩn bị kiến thức về vận dụng Toán học vào thực tiễn cho sinh viên ngành su phạm Toán là rất quan trọng để triển khai nội dung này vào việc dạy học Toán ở truờng phổ thông. Trong bài viết này, chúng tôi trình bày nguyên lý và xu huớng của việc dạy học có nội dung thưc tiễn trong môn Toán, và đề xuất một số tình huống có thể đua bài toán có nội dung thục tiễn vào quá trình giảng dạy cho sinh viên ngành Toán ở truòng Cao đẳng Su pham.

Tù̀ khóa: Bài toán,nội dung, thực tiễn, sinh viên sur phạm toán

\begin{abstract}
Math as well as other science subjects are arisen from practice and base on pratice for the development of motivation, and they come back to serve the purpose of addressing practical issues. This is one of foundations for mathemaric teaching and learning in conjunction with practice. The preparation and application mathematic knowledge into practice for mathematic students are essential to implement this area in teaching Math subject in high schools. In this paper, we present principles and trends of practical teaching in Math subject and propose some posibilities that can apply practical mathematic exercises into teaching process for students who are studying mathematic degree in teacher training colleges.
\end{abstract}

Keywords: mathematic esxercises; practical content; mathematic pedagogic students

\section{Mở đầu}

Nâng cao năng lực vận dụng Toán học (TH) vào thực tiễn cho học sinh (HS) là một trong những mục tiêu cơ bản của dạy học Toán ở Trung học cơ sở (THCS). Nét nổi bật của dạy học Toán ở bậc phổ thông ngày nay là chú trọng phát triển tư duy, coi trọng tính hệ thống của tri thức và gắn chặt tri thức truyền thụ với đời sống thực tiễn. Điều khẳng định của các tác giả R.Courant, H.Robbins: "Việc thiết lập lại mối liên hệ giữa tri thức thuần túy và tri thức ứng dụng, sự cân bằng lành mạnh giữa tính khái quát trừu tượng và tính cụ thể phong phú là nhiệm vụ của $\mathrm{TH}$ trong một tương lai gần" [1], đang trở thành hiện thực. Ở nước ta, nguyên tắc xây dựng chương trình của môn Toán ở THCS phải đảm bảo các mục tiêu:

\footnotetext{
* Trường Đại học Tân Trào
} 
- Tính chỉnh thể của chương trình môn Toán trong nhà trường phổ thông: chương trình Toán THCS phải được xây dựng cùng với chương trình Toán Tiểu học và chương trình toán Trung học phổ thông (THPT) theo một hệ thống quan điểm chỉ đạo chung; đảm bảo tính hệ thống giữa các lớp trong toàn cấp THCS.

- Không quá coi trọng tính cấu trúc, tính chính xác của hệ thống kiến thức Toán học trong chương trình; hạn chế đưa vào chương trình những kết quả có ý nghĩa lý thuyết thuần túy và các phép chứng minh dài dòng, phức tạp không phù hợp với đại đa số HS. Tăng tính thực tiễn và tính sư phạm, tạo điều kiện để HS được luyện tập, thực hành, rèn luyện kĩ năng tính toán và vận dụng các kiến thức $\mathrm{TH}$ vào đời sống và vào các môn học khác [5].

Trong những năm đầu của thế kỷ XXI, các nước trong tổ chức OECD (Organisation for Economic Cooperation and Development: Tổ chức Hợp tác và Phát triển Kinh tế) đã đưa ra chương trình đánh giá quốc tế PISA (Programme for International Student Assessment) cho HS phổ thông ở lứa tuổi 15. PISA nhằm tìm câu trả lời cho câu hỏi: Cái gì có thể coi là đầu ra - kết quả cuối cùng trong nhà trường của một xã hội hiện đại (What should be the final outcomes of Schooling in modern Society). Phạm vi đánh giá năng lực học sinh của PISA có liên quan đến khả năng phân tích, suy luận kết nối ý tưởng một cách có hiệu quả khi họ đặt câu hỏi, lập công thức, giải quyết vấn đề trong các tình huống. Đánh giá của PISA tập trung vào vấn đề thực tế, chuyển những tình huống dạng này về vấn đề điển hình có thể gặp phải trong lớp học. Chẳng hạn, khi mua bán, tham gia giao thông, khi giải quyết những công việc liên quan đến chính trị, xã hội,... mà ở đó trình độ TH nhất định sẽ tạo điều kiện thuận lợi để giải quyết vấn đề [6].

Theo tác giả của [4] cho rằng: Ngày nay, trong bối cảnh kinh tế hội nhập và cạnh tranh toàn cầu, nâng cao và bảo đảm chất lượng giáo dục là một trong những yêu cầu mà một đất nước cần phải quan tâm. Các chương trình đánh giá HS quốc tế phần lớn không chỉ đơn thuần là sự xếp hạng mà nó còn nêu ra được những điểm mạnh và điểm yếu của hệ thống giáo dục của các quốc gia tham gia khảo sát để không ngừng cải thiện chất lượng giáo dục. Hiểu biết $\mathrm{TH}$ xác định như là năng lực của HS để xác định và hiểu vai trò của TH trong cuộc sống, để đưa ra những phán xét có cơ sở, để sử dụng và gắn kết với TH theo các cách đáp ứng nhu cầu của cuộc sống. Đánh giá Toán PISA mong muốn tìm kiếm học sinh tuổi 15 cần có những hiểu biết TH nào để chuẩn bị cho cuộc sống trưởng thành mà các em sắp sửa bước vào. Tổng thư ký của $\mathrm{OECD}$, Angel Gurria, phát biểu rằng: "PISA là một công cụ hỗ trợ các chính phủ đưa ra các lựa chọn chính sách giáo dục. Ông cho rằng “điều tra PISA không chỉ để xếp hạng, điều quan trọng là nó chỉ ra điểm mạnh, điểm yếu của hệ thống giáo dục của các quốc gia, đồng thời chỉ ra hướng đi cải cách hệ thống giáo dục ấy”.

Theo tác giả của [3] đề xuất về chương trình và sách giáo khoa Toán phổ thông sau 2015 là: Nội dung Toán ở nhà trường phổ thông không chỉ trang bị cho HS các kiến thức để biết (declarative knowledge) mà còn phải trang bị cho HS kiến thức để làm (procedural knowledge) và kiến thức để biết khi nào sử dụng kiến thức nào (conditional knowledge). Nội dung $\mathrm{TH}$ ở nhà trường phổ thông phải là môi trường rèn luyện năng lực giải quyết vấn đề (mathematics as problemsolving) và ứng dụng TH trong cuộc sống hàng ngày (everyday life mathematics). 
Về nhiệm vụ của các trường Sư phạm, Bộ trưởng Bộ Giáo dục và Đào tạo đã ban hành chỉ thị số 15/1999/CT-BGD\&ĐT ngày 20/04/1999 về việc "Đẩy mạnh hoạt động đổi mới phuoong pháp giảng dạy và học tập trong các truờng su phạm”, chỉ thị nhấn mạnh sự cần thiết phải đẩy mạnh nghiên cứu khoa học về đổi mới nội dung và phương pháp giảng dạy, học tập ở trường sư phạm gắn với yêu cầu đổi mới giáo dục phổ thông. Như vậy các trường sư phạm cần phải trang bị cho giáo viên Toán tương lai tiềm năng khai thác các yếu tố thực tiễn trong dạy học Toán như thế nào để họ thực hiện một cách có hiệu quả nguyên lý giáo dục "làm rõ mối liên hệ giữa TH và thực tiễn" trong dạy học Toán THCS sau khi tốt nghiệp? Các kiến thức về ứng dụng TH vào môn học khác, vào thực tiễn đời sống có thể khai thác từ những nguồn nào? Câu trả lời đó là khai thác thông qua những nội dung của các học phần Toán cơ bản và Toán cơ sở trong chương trình đào tạo giáo viên Toán THCS. Chẳng hạn, các học phần: Phép tính vi phân, tích phân hàm số một biến số; Phép tính vi phân, tích phân hàm số nhiều biến số; Đại số tuyến tính; Xác suất thống kê,... là những học phần có thể dạy học theo hướng tăng cường vận dụng $\mathrm{TH}$ vào thực tiễn. Điều này đồng nghĩa với việc Giảng viên thực hiện nguyên lý giáo dục "làm rõ mối liên hệ giữa $\mathrm{TH}$ và thực tiễn" trong dạy học Toán cho Sinh viên hệ Cao đẳng sư phạm Toán

Các học phần Toán cơ bản và Toán cơ sở trong chương trình đào tạo GV THCS hiện nay có tính trừu tượng khá cao. Các khái niệm được định nghĩa chính xác, các phép chứng minh chặt chẽ, các ví dụ mang tính chất $\mathrm{TH}$ thuần túy. Như vậy sinh viên sẽ gặp khó khăn trong việc "làm rõ mối liên hệ giữa TH và thực tiễn" trong dạy học Toán THCS sau này. Để đáp ứng đòi hỏi của thực tiễn dạy học Toán ở THCS trong giai đoạn hiện nay là đào tạo thế hệ trẻ có ý thức và khả năng ứng dụng TH vào đời sống thực tiễn và tham gia vào các chương trình điều tra PISA đối với các HS ở độ tuổi 15, để đánh giá khả năng ứng dụng kiến thức và kỹ năng học được vào các tình huống thực tiễn của cuộc sống thì các trường Sư phạm cần phải chuẩn bị tiềm năng kiến thức về vận dụng $\mathrm{TH}$ vào thực tiễn cho sinh viên Toán trong toàn bộ chương trình đào tạo.

Trong bài viết này, chúng tôi xin đề xuất một số tình huống phát triển từ thực tế thành bài toán trong dạy học Toán cho sinh viên hệ Cao đẳng sư phạm Toán.

\section{Bài toán thực tế được xây dựng nhằm gọi động cơ học tập}

Gợi động cơ trong dạy học là làm cho người học có ý thức về ý nghĩa của những hoạt động học tập và của đối tượng hoạt động nhằm làm cho những mục tiêu sư phạm biến thành những mục tiêu của cá nhân HS [2]. Việc gợi động cơ học tập xuất phát từ thực tế giúp người học nhận rõ việc nhận thức và cải tạo thế giới đã đòi hỏi phải suy nghĩ và giải quyết các vấn đề $T H$ như thế nào, tức là nắm rõ $\mathrm{TH}$ bắt nguồn từ những nhu cầu của thực tế. Vì vậy, vấn đề xây dựng bài toán thực tế qua gợi động cơ trong học tập rất có ý nghĩa trong việc phát triển năng lực vận dụng TH vào thực tiễn.

Ví dụ 1: Khi dạy định nghĩa hàm số một biến số, nhiều biến số trong các học phần Phép tính vi phân, tích phân hàm số một biến số, Phép tính vi phân, tích phân hàm số nhiều biến số, chúng ta xét tình huống thực tế:

Trong hoạt động sản xuất kinh doanh, các nhà quản trị quan tâm đến doanh thu. Giả sử sản phẩm được bán với giá $\mathrm{P}$ và khối lượng bán trong tháng là $\mathrm{Q}$ thì tổng doanh thu (Total Revenue): 
$\mathrm{TR}=\mathrm{P} . \mathrm{Q}$, trong đó $\mathrm{TR}, \mathrm{P}, \mathrm{Q}$ đều là ký hiệu cho các biến kinh tế. Tức là chúng ta tính doanh thu phụ thuộc vào giá và số lượng, bất cứ một thay đổi nào của giá hoặc số lượng cũng làm thay đổi doanh thu. Như vậy, khi tính một biến kinh tế này phụ thuộc vào một hay nhiều biến kinh tế khác, nghĩa là chúng ta đã xác lập một quan hệ hàm giữa các biến kinh tế.

Xuất phát từ tình huống trên, chúng ta có thể phát triển thành tình huống tổng quát hơn khi gọi $\mathrm{Q}$ là sản phẩm quốc gia, $\mathrm{N}$ là yếu tố tự nhiên, $\mathrm{K}$ là $\mathrm{T}$ bản, $\mathrm{L}$ là nhân công, $\mathrm{S}$ là khoa học kỹ thuật, $E$ là môi trường xã hội thì hàm số sản xuất là: $Q=f(K, L, N, S, E)$. Như vậy, trong trường hợp này hàm số sản xuất $\mathrm{Q}$ phụ thuộc vào 5 biến số (hàm nhiều biến số).

\section{Bài toán thực tế được xây dựng trong giai đoạn xây dựng lý thuyết của bài học}

Một trong những động lực thúc đẩy sự phát triển của các lý thuyết TH và giúp hoàn thiện quá trình xây dựng một mức chặt chẽ thống nhất cho toàn bộ toán học là lĩnh vực ứng dụng của $\mathrm{TH}$, trong đó có giải quyết những tình huống mới (có thể từ thực tế) nảy sinh. Vì vậy, trong giai đoạn xây dựng lý thuyết của bài học cần thiết lập những bài toán với những yêu cầu mới từ một tình huống nào đó để phát triển hệ thống lý thuyết TH của bài học.

Ví dụ 2: Để dạy kiến thức Trung bình mẫu trong học phần Xác suất thống kê, chúng tôi yêu cầu sinh viên thống kê điểm thi môn Đại số tuyến tính của lớp. Sau đó tính điểm trung bình của lớp bằng cách lấy tổng điểm chia cho tổng số sinh viên mà sinh viên đã biết cách tính. Từ đó phát biểu bài toán tổng quát: Giả sử cho $\left(\mathrm{X}_{1}, \mathrm{X}_{2}, \ldots, \mathrm{X}_{\mathrm{n}}\right)$ là mẫu ngẫu nhiên, trung bình mẫu được tính bởi công thức: $\bar{X}=\frac{1}{n} \sum_{i=1}^{n} x_{i}$

Mặc khác yêu cầu sinh viên thống kê số lần xuất hiện điểm số, từ đó hình thành bảng phân bố tần số. Khi đó tính điểm trung bình bằng cách nhân từng điểm số với tần số rồi mới cộng chúng lại. Tổng này sẽ chia với tổng các tần số, ta được điểm trung bình. Từ đó hình thành công thức tính tổng quát:

Cho mẫu ngẫu nhiên dưới dạng tần số:

\begin{tabular}{|c|c|c|c|c|}
\hline $\mathrm{X}$ & $\mathrm{X}_{1}$ & $\mathrm{X}_{2}$ & $\cdots$ & $\mathrm{X}_{\mathrm{k}}$ \\
\hline $\mathrm{n}_{\mathrm{i}}$ & $\mathrm{n}_{1}$ & $\mathrm{n}_{2}$ & $\ldots$ & $\mathrm{n}_{\mathrm{k}}$ \\
\hline
\end{tabular}

Khi đó trung bình mẫu được tính: $\bar{X}=\frac{\sum_{i=1}^{k} n_{i} X_{i}}{\sum_{i=1}^{k} n_{i}}$.

Từ tình huống cụ thể sinh viên đã hình thành công thức tính tổng quát và biết được điểm trung bình thi môn Đại số tuyến tính của lớp là cao hay thấp.

\section{Bài toán thực tế được xây dụng trong giai đoạn củng cố bài học}

Trong $\mathrm{TH}$, củng cố kiến thức diễn ra dưới các hình thức luyện tập, đào sâu, ứng dụng, hệ thống hoá và ôn tập. Sau khi hoàn chỉnh một phần lý thuyết bài học, người học có thêm những kiến 
thức mới để có những hướng mới phát triển bài toán ban đầu. Phát triển tình huống thực tế khi củng cố kiến thức bài học giúp nhìn nhận tình huống thực tế đã xét trong giai đoạn trước đó một cách đầy đủ, phong phú và tổng quan hơn [2].

Ví dụ 3: Sau khi sinh viên học xong bài Hệ phương trình tuyến tính Cramer của học phần Đại số tuyến tính, ngoài ví dụ là một hệ phương trình tuyến tính Cramer thuần túy $\mathrm{TH}$, chúng tôi cung cấp một tình huống trong kinh tế vận dụng kiến thức bài vừa học đó là Mô hình cân bằng thị trường có 3 loại sản phẩm như sau:

Bài toán: Có 3 sản phẩm, lượng cung $\left(\mathrm{Q}_{\mathrm{S}}\right)$ và lượng cầu $\left(\mathrm{Q}_{\mathrm{D}}\right)$ được cho cụ thể:

Sản phẩm 1: $\quad \mathrm{Q}_{\mathrm{S}_{1}}=8 \mathrm{p}_{1}+\mathrm{P}_{2}+\mathrm{P}_{3}-40$ và $\mathrm{Q}_{\mathrm{D}_{1}}=-11 \mathrm{p}_{1}+3 \mathrm{p}_{2}+2 \mathrm{p}_{3}+133$

Sản phẩm 2: $\quad \mathrm{Q}_{\mathrm{S}_{2}}=\mathrm{p}_{1}+15 \mathrm{P}_{2}-23 \quad$ và $\quad \mathrm{Q}_{\mathrm{D}_{2}}=2 \mathrm{p}_{1}-7 \mathrm{p}_{2}+\mathrm{p}_{3}+70$

Sản phẩm 3: $\quad \mathrm{Q}_{\mathrm{S}_{3}}=-\mathrm{p}_{1}+7 \mathrm{P}_{3}-20 \quad$ và $\quad \mathrm{Q}_{\mathrm{D}_{3}}=2 \mathrm{p}_{2}-10 \mathrm{p}_{3}+79$

Trong đó $\mathrm{p}_{1}$ là giá bán sản phẩm $1, \mathrm{p}_{2}$ là giá bán sản phẩm $2, \mathrm{p}_{3}$ là giá bán sản phẩm 3 . Tìm điểm cân bằng trên thị trường?

Chúng ta đã biết, thị trường cân bằng khi cung và cầu bằng nhau, tức là:

$$
\left\{\begin{array} { l } 
{ \mathrm { Q } _ { \mathrm { S } _ { 1 } } = \mathrm { Q } _ { \mathrm { D } _ { 1 } } } \\
{ \mathrm { Q } _ { \mathrm { S } _ { 2 } } = \mathrm { Q } _ { \mathrm { D } _ { 2 } } } \\
{ \mathrm { Q } _ { \mathrm { S } _ { 3 } } = \mathrm { Q } _ { \mathrm { D } _ { 3 } } }
\end{array} \Leftrightarrow \left\{\begin{array}{l}
19 \mathrm{p}_{1}-2 \mathrm{p}_{2}-\mathrm{p}_{3}=173 \\
-\mathrm{p}_{1}+22 \mathrm{p}_{2}-\mathrm{p}_{3}=93 \\
-\mathrm{p}_{1}-2 \mathrm{p}_{2}+17 \mathrm{p}_{3}=99
\end{array}\right.\right.
$$

Hệ phương trình (1) là hệ Cramer vì có số phương trình bằng số ẩn số, bằng 3 và có ma trận hệ số $A=\left(\begin{array}{ccc}19 & -2 & -1 \\ -1 & 22 & -1 \\ -1 & -2 & 17\end{array}\right)$, $\operatorname{det}(\mathrm{A})=-398 \neq 0$. Nên hệ phương trình $(1)$ có duy nhất nghiệm: ( $\mathrm{p}_{1}$, $\left.\mathrm{p}_{2}, \mathrm{p}_{3}\right)=(10,5,7)$. Vậy điểm cân bằng thị trường đạt được tại $\mathrm{p}_{1}=10, \mathrm{p}_{2}=5, \mathrm{p}_{3}=7$. Như vậy thông qua việc giải bài toán trên, sinh viên đã được áp dụng kiến thức vừa học vào một tình huống thực tế.

\section{Bài toán thực tế được xây dựng trong quan điểm thực hiện vấn đề liên môn}

Thực hiện quan điểm liên môn trong xây dựng bài toán thực tế sẽ dẫn đến việc xem xét một tình huống thực tế bằng các kiến thức của những môn học khác nhau để được cung cấp thêm các giả thiết, các vật liệu, các công cụ khác nhau giúp nhìn nhận tình huống thực tế đó trên nhiều phương diện nhằm xây dựng phong phú các bài toán thực tế mà thiếu mối liên hệ liên môn thì chưa đủ điều kiện để nhìn nhận tình huống thực tế đó ở các góc độ khác.

Ví dụ 4: Khi dạy định nghĩa hàm số nhiều biến số trong học phần Phép tính vi phân, tích phân hàm số nhiều biến số, chúng ta xét tình huống thực tế đó là: Quả bom nguyên tử nổ đã tạo thành đám mây hình nấm [7], hình 1. 


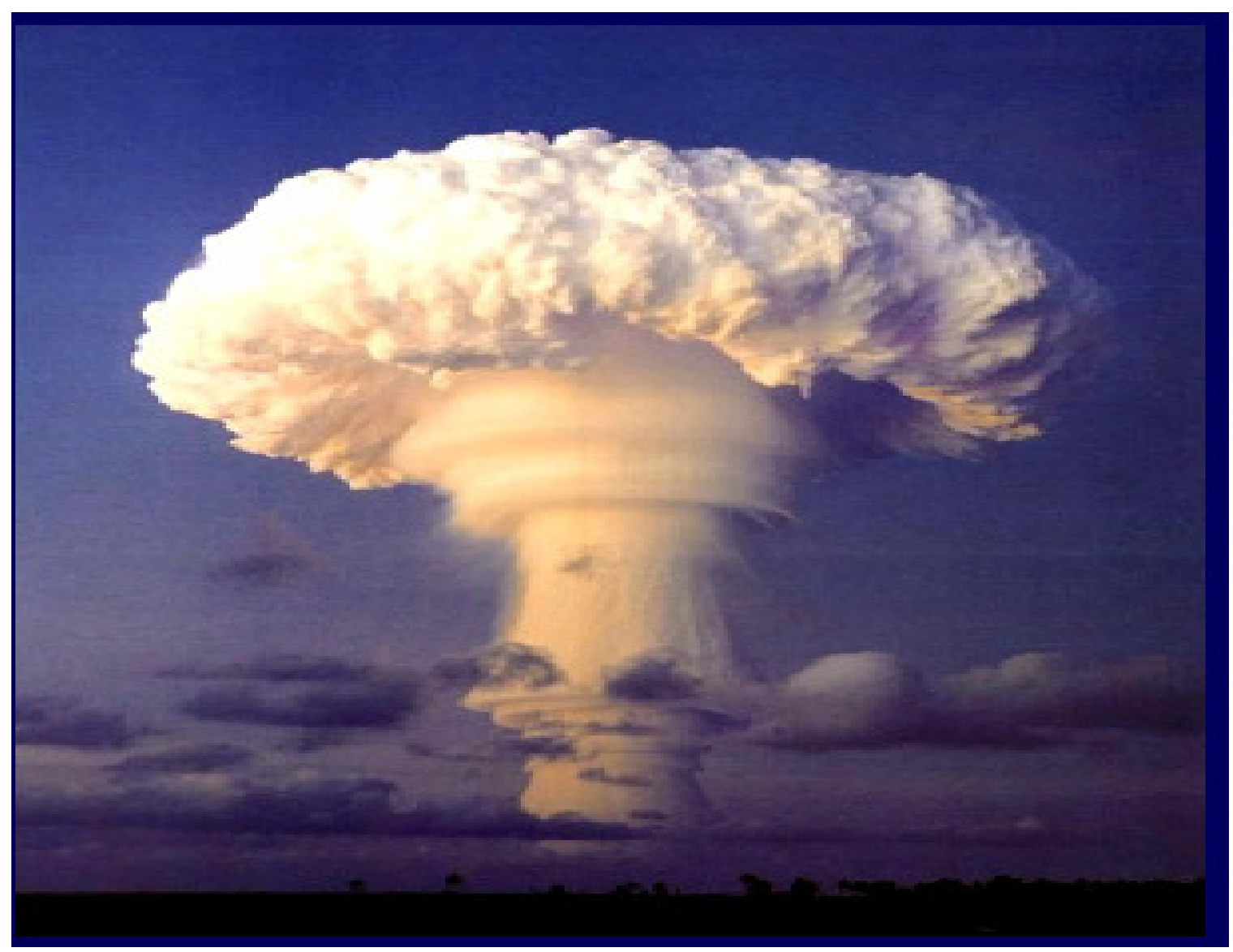

Hình 1 (Truckee, june 9, 1962, Airdrop, 210kt)

Và quá trình diễn ra của quả bom nguyên tử nổ trong giây đầu tiên hình 2 .

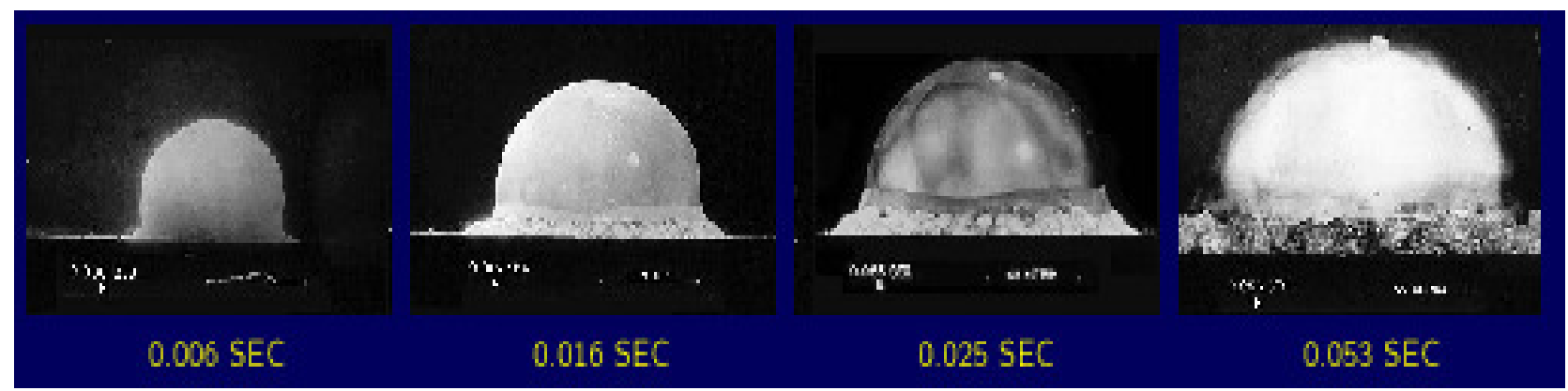

Hìn 2

Quá trình diễn ra của quả bom nguyên tử nổ có thể được đơn giản hóa là một dạng nhiều năng lượng được phát ra tại một thời điểm. Do bán kính đám mây hình nấm do quả bom nguyên tử nổ tạo thành là $\mathrm{R}$, bán kính tăng theo thời gian. Như chúng ta biết, $\mathrm{R}$ có liên quan đến thời gian $\mathrm{t}$, năng lượng phát ra $\mathrm{E}$, độ dày không khí xung quanh $\rho_{0}$ và áp suất $\mathrm{P}_{0}$. Vậy: $\mathrm{R}=\mathrm{f}\left(\mathrm{t}, \mathrm{E}, \mathrm{\rho}_{0}, \mathrm{P}_{0}\right)$. Trong trường hợp này $\mathrm{R}$ là một hàm số bốn biến số. Ví dụ trên cho thấy mối liên hệ giữa $\mathrm{TH}$ và Vật lý là hết sức chặt chẽ.

\section{Kết luận}

Toán học phát sinh từ thực tiễn, lấy thực tiễn làm động lực phát triển và làm mục tiêu phục vụ. Đây là một trong những cơ sở quan trọng cho việc dạy và học Toán kết nối với thực tiễn. Để 
đáp ứng đòi hỏi của thực tiễn dạy học Toán ở trường THCS trong giai đoạn hiện nay, là đào tạo thế hệ trẻ có ý thức và khả năng ứng dụng TH vào đời sống thực tiễn cuộc sống, tham gia vào các chương trình đánh giá PISA đối với các học sinh ở độ tuổi 15 thì các trường Sư phạm cần phải chuẩn bị tiềm năng kiến thức về vận dụng TH vào thực tiễn cho sinh viên Toán trong toàn bộ các môn Toán.

\section{TÀI LIỆU THAM KHẢO}

1. R. Courant và H. Robbins, Toán học là gì - Tập 1 (người dịch: Hàn Liên Hải), Nxb Khoa học kỹ thuật, H. 1984.

2. Nguyễn Bá Kim (2006), Phưong pháp day học môn Toán, Nxb ĐHSP.

3. Trần Luận (2011), "Một số suy nghĩ về chương trình và sách giáo khoa môn Toán PTTH ở nước ta từ cải cách đến đổi mới và những đề xuất cho chương trình sau năm 2015”, Kỷ yếu Hội thảo Quốc gia về giáo dục Toán học ở truờng phổ thông, Nxb Giáo dục Việt Nam, Hà Nội.

4. Trần Vui (2008), "Đánh giá hiểu biết Toán cho học sinh 15 tuổi”, Chuoong trình đánh giá hoc sinh Quốc tế (PISA), Nxb Giáo dục, Hà Nội.

5. Chưong trình THCS các môn Toán, Tin học (Ban hành kèm theo Quyết định số 03/2002/QĐ - Bộ GD \& ĐT ngày 24 tháng 1 năm 2002 của Bộ trưởng Bộ Giáo dục và Đào tạo), NXB Giáo dục, Hà Nội.

6. PISA (Programme for International Student Assessment), Tài liệu Trung tâm nghiên cứu GDPT- Viện Khoa học Giáo dục Việt Nam, H. 6/2009.

7. Tao Hong, Application of Math in Real Life, Department of Physics and Astronomy, The Jhons Hopkins University.

https://www.wiziq.com/tutorial/564-Application-of-Math-in-Real-Life 